\title{
Improving the bonding between henequen fibers and high density polyethylene using atmospheric pressure ethylene-plasma treatments
}

\author{
A. Aguilar-Rios ${ }^{1}$, P. J. Herrera-Franco ${ }^{1}$, A. de J. Martínez-Gómez ${ }^{2}$, A. Valadez-González $^{1 *}$ \\ ${ }^{1}$ Centro de Investigación Científica de Yucatán, A.C. 130 No.43, Chuburná de Hidalgo, 97200 Mérida, Yucatán, México \\ ${ }^{2}$ Departamento de Ingeniería Química Universidad de Guadalajara, Blvd. Marcelino García Barragán, 1421 Guadalajara \\ Jalisco, México
}

Received 17 December 2013; accepted in revised form 19 March 2014

\begin{abstract}
In order to improve the bonding between henequen fibers (Agave fourcroydes) and High Density Polyethylene (HDPE), they were treated in an ethylene-dielectric barrier discharge (DBD) plasma operating at atmospheric pressure. A $2^{3}$ factorial experimental design was used to study the effects of the plasma operational parameters, namely, frequency, flow rate and exposure time, over the fiber tensile mechanical properties and its adhesion to HDPE. The fiber-matrix Interfacial Shear Strength (IFSS) was evaluated by means of the single fiber pull-out test. The fiber surface chemical changes were assessed by photoacoustic Fourier transform infrared spectroscopy (PAS-FTIR) and the changes in surface morphology with scanning electron microscopy (SEM). The results indicate that individual operational parameters in the DBD plasma treatment have different effects on the tensile properties of the henequen fibers and on its bonding to HDPE. The SEM results show that the plasma treatment increased the roughness of the fiber surface. The FTIR result seems to indicate the presence of a hydrocarbon-like polymer film, bearing some vinyl groups deposited onto the fibers. These suggests that the improvement in the henequen-HDPE bonding could be the result of the enhancement of the mechanical interlocking, due the increment in roughness, and the possible reaction of the vinyl groups on the film deposited onto the fiber with the HDPE.
\end{abstract}

Keywords: adhesion, atmospheric dielectric barrier discharge, henequen fiber, HDPE, IFSS

\section{Introduction}

Recent environmental concerns have triggered the use of natural fibers because they fulfil the sustainability criteria for development in the third millennium, and are readily available from renewable sources at a low price. Natural fibers like henequen, sisal, jute, coir, etc. possess physical and mechanical properties that make them attractive as reinforcing materials for the substitution of engineering manmade fibers which are neither biodegradable nor renewable. Additionally, their hollow tubular structure enhances their acoustic and thermal insulating properties, which could lead to energy saving in several industrial applications [1-8].

Several studies on henequen fibers (Agave fourcroydes) reinforced polyolefins composites have been conducted in the last few years. The most important drawback to overcome for a more ample use of these hydrophilic natural fibers in composites is their chemical incompatibility with hydrophobic thermoplastic polyolefins. It is known that incompatibility at the fiber-matrix interface limits the stress transfer capability, meaning that the reinforcing potential of natural fibers cannot be exploited to

\footnotetext{
*Corresponding author, e-mail: avaladez60@gmail.com

(C) BME-PT
} 
their full extent, especially for short fiber composites [9-14].

Several chemical-based approaches have been used to improve the compatibility between natural fibers with different polymeric matrices, e.g. alkali treatments (mercerization), silanization, acetylation, benzoylation, maleated coupling agents, isocyanate treatments and grafting of synthetic polymers $[1,3,7,12$, 13, 15-17]. Silanization is by far most effective fiber surface treatment, judged by the improvements in material property increases, above a $100 \%$ in the tensile and flexural strengths $[11,12]$. However, even though the wet chemical treatments of fiber surfaces have been somewhat successful in improving the interfacial bonding, there are still problems related to the appropriate handling and disposal of the large amounts of hazardous chemicals that are often involved and concerned with environmental pollution problems. These problems have limited a wider industrial application of chemical fiber surface treatments [4, 16-20]. Cold plasma is a solvent-free technique with no liquid waste generated and can therefore be considered as an environmentally sound method. Also, the plasma-based surface modification is restricted to a thin depth of the material, e.g. the bulk properties of materials are retained and it uses small quantities of monomers. The surface functionalization can be carried out in one step and several functional groups, e.g. $\mathrm{OH}$, $\mathrm{COOH}, \mathrm{NH}_{2}, \mathrm{CNH}$, can be grafted on polymer surface depending on monomer selected [21-25]. de Valence et al. [26] studied the effect of cold air plasma treatment on the hydrophilicity of electrospun polycaprolactone scaffolds in order to improve cell-material interactions and promote better tissue regeneration for biodegradable vascular graft applications. They pointed out that the plasma treatment significantly increased the hydrophilicity of the scaffold and accelerated tissue regeneration without compromising the mechanical strength, which are valuable advantages for vascular tissue engineering. Kaklamani et al. [27] pointed out that the active screen plasma nitridizing (ASPN) treatment of UHMWPE enhanced cell attachment without altering the mechanical properties and topography of the polymer surface. They treated the UHMWPE with a gas mixture $80 \% \mathrm{~N}_{2}$ and $20 \% \mathrm{H}_{2}(\mathrm{v} / \mathrm{v})$ at $2.5 \mathrm{mbar}$ pressure and $90^{\circ} \mathrm{C}$ followed by growth of $3 \mathrm{~T} 3$ fibroblasts on the treated and untreated polymer surfaces. The chemical properties of the ASPN- treated UHMWPE surface were studied using Xray photoelectron spectroscopy, revealing the presence of $\mathrm{C}-\mathrm{N}, \mathrm{C}=\mathrm{N}$, and $\mathrm{C} \equiv \mathrm{N}$ chemical bonds. Parvinzadeh Gashti et al. [28] carried out the plasma functionalization of PET using $\mathrm{Ar} / \mathrm{O}_{2}(4: 1)$ and $\mathrm{NH}_{3} /$ $\mathrm{C}_{2} \mathrm{H}_{4}$ (1:1) gas mixtures followed by incubation in simulated body fluids (SBF) in order to investigate the effect of the cold plasma process in the formation of bone-like hydroxyapatite (HAp). Their results suggest that $\mathrm{Ar} / \mathrm{O}_{2}$ and $\mathrm{NH}_{3} / \mathrm{C}_{2} \mathrm{H}_{4}$ plasmas as potentially useful tools for bone tissue regeneration procedures. The use of the dielectric barrier dischargeprocess (DBD) to generate a reactive cold plasma to modify the surface chemistry of synthetic a natural materials has been explored by several groups [24, 25]. It is characterized by relatively low engineering costs, high speed, and simplicity compared to lowpressure (vacuum) plasma techniques. Another advantage from an industrial viewpoint is that continuous in-line processing can easily be performed. The control of external plasma operational parameters, such as frequency of discharges, exposure time and flow rate of the monomer makes this technique very promising for modifying the surface chemistry and topography of henequen fibers, which can thereby be tuned to design henequen surfaces compatible with high density polyethylene. In this work we used DBD treatments with ethylene at atmospheric pressure to modify the surface properties of henequen fibers (HF), (Agave fourcroydes) and the main goal was to improve their adhesion to HDPE. A $2^{3}$ factorial experimental design was used to study the effects of the plasma parameters, frequency, flow rate and exposure time, onto the HF tensile mechanical properties and its adhesion to High Density Polyethylene (HDPE). The chemical functionalization and topography of the surfaces were analyzed by means of PAS-FTIR and SEM to better understand the surface modification.

\section{Experimental}

\subsection{Materials}

Henequen fibers with an average diameter of $180 \mu \mathrm{m}$ and average length of $9 \mathrm{~cm}$, supplied by Desfibradora Yucateca, S.A. (DESFIYUSA Co.) of Mérida, Yucatán, México were used. High density polyethylene, HDPE (Petrothene) extrusion grade, was supplied by Quantum Chemical Inc. A melt flow index of $0.33 \mathrm{~g} / 10 \mathrm{~min}$ was determined using ASTM standard D-1238-79 at $190^{\circ} \mathrm{C}$ and a weight 
of $2160 \mathrm{~g}$. A density of $0.96 \mathrm{~g} / \mathrm{cm}^{3}$ was determined using ASTM standard D-792-86 and benzene as an immersion liquid. The melting point $\left(135^{\circ} \mathrm{C}\right)$ was determined in a DSC-7 Perkin Elmer calorimeter. Ethylene $\left(\mathrm{C}_{2} \mathrm{H}_{4}\right)(99 \%$, INFRA, Guadalajara, Mexico) and UHP Helium (99.99\%, INFRA, Guadalajara, Mexico) were used as received without further purification.

\subsection{Plasma treatments and design of experiments}

\subsubsection{Dielectric barrier discharge treatments}

Dielectric barrier discharges were generated in a parallel-plate reactor prototype described elsewhere [29]. In a typical treatment, once the discharge gap and the frequency had been selected, $9 \mathrm{~cm}$ long henequen fibers were vacuum-oven dried, $\left(60^{\circ} \mathrm{C}\right.$, 135 Torr, $12 \mathrm{~h}$ ) and placed on the reactor, and then, the reactor was closed. Helium was allowed to flow $(2 \mathrm{~L} / \mathrm{min}$ ) for a period of $5 \mathrm{~min}$ to free the reactor chamber from air and other impurities. The ethylene reagent was then fed for $3 \mathrm{~min}$ and then the discharge was ignited, selecting both flow and time of discharge according to the experimental design. All the reactions were carried out at atmospheric pressure and room temperature $\left(25^{\circ} \mathrm{C}\right)$. The reagent was allowed to flow for one more minute in order to quench the free radicals, and helium was fed again at $2 \mathrm{~L} / \mathrm{min}$ for $5 \mathrm{~min}$ to evacuate the reaction chamber. The henequen samples were collected and stored (overnight) in plastic bags until ready for further analysis. Xylene extraction of henequen fibers in a Soxhlet apparatus for $6 \mathrm{~h}$ after the ethylene-plasma treatments was carried out at $120^{\circ} \mathrm{C}$ for $12 \mathrm{~h}$ in order to make sure that the deposited layers could not be easily removed by physical or chemical means.

\subsubsection{Statistical experimental design}

A common method used to investigate the effects of the values of the operational parameters (factors) on a process is the usual approach of changing the value of one factor at a time and noting its influence on a given characteristic of the final product (response). However, this method has some disadvantages: it requires a large number of trials and it does not reveal the possible interactions between factors. In contrast, factorial experimental designs can be efficient when several factors (more than two) are under study. By factorial design, it means that in each complete trial all possible combinations of the levels of the factors are investigated. The factors are commonly used at two levels. Normally, it is assumed that the response is approximately linear over the range of the factor level chosen. In a twolevel factorial design a ( $2^{\mathrm{k}}$ factorial design), it is understood that the measured property $y$ (the response of the system) can be related with the experimental variables through the polynomial first order regression model shown in Equation (1):

$$
\begin{aligned}
y= & b_{0}+b_{1} X_{1}+b_{2} X_{2}+b_{3} X_{3}+b_{12} X_{1} X_{2}+b_{13} X_{1} X_{3}+ \\
& b_{23} X_{2} X_{3}+b_{123} X_{1} X_{2} X_{3}+\varepsilon
\end{aligned}
$$

where, $X_{\mathrm{i}}$ is the coded values of the considered factors.

A two-level full factorial design $2^{3}$ with five central points was employed to investigate the effects of the external plasma operational parameters: frequency of discharges $(A)$, plasma exposure time $(B)$ and the flow rate of ethylene $(C)$ over the tensile mechanical properties of henequen fibers and the Interfacial Shear Strength (IFSS) between henequen fibers and the HDPE. The levels of the three independent variables studied are indicated in Table I. They were selected on the basis of preliminary studies of this polymerization system [29].

For the convenience of handy data processing and to simplify calculation of the regression coefficients, the independent variables investigated were re-coded so as to give normalized variables varying within the range of $[-1,1]$. Thus, if $A$ denotes the natural variable plasma frequency; $B$ the natural variable exposure time of the fiber and $C$ the ethylene flow rate, then the coded variables are calculated as Equation (2):

$$
\begin{aligned}
& X_{1}=\frac{A-145 \mathrm{~Hz}}{25 \mathrm{~Hz}}, X_{2}=\frac{B-4.5 \mathrm{~min}}{3.5 \mathrm{~min}}, \\
& X_{3}=\frac{C-0.604 \mathrm{~L} / \mathrm{min}}{0.414 \mathrm{~L} / \mathrm{min}}
\end{aligned}
$$

The standard experimentation matrix is shown in Table 2. Columns 2 to 4 give the variable levels

Table 1. Levels of factors in experimental design

\begin{tabular}{|c|c|c|c|}
\hline \multirow{2}{*}{ Levels } & \multicolumn{3}{|c|}{ Factor } \\
\cline { 2 - 4 } & $\begin{array}{c}\text { Frequency (A) } \\
{[\mathbf{H z}]}\end{array}$ & $\begin{array}{c}\text { Exposure time (B) } \\
{[\mathbf{m i n}]}\end{array}$ & $\begin{array}{c}\text { Flow rate (C) } \\
{[\mathbf{L} / \mathbf{m i n}]}\end{array}$ \\
\hline Lower (-1) & 120 & 1.0 & 0.204 \\
\hline Higher (+1) & 170 & 8.0 & 1.018 \\
\hline
\end{tabular}


Table 2. Experimental variables in the factorial experimental design $2^{3}$ with five central points

\begin{tabular}{|c|c|c|c|c|c|c|c|c|c|}
\hline $\begin{array}{c}\text { Run } \\
\text { (Standard order) }\end{array}$ & $\mathbf{X}_{1}$ & $\mathbf{X}_{2}$ & $\mathbf{X}_{3}$ & $\begin{array}{c}\mathrm{A} \\
{[\mathrm{Hz}]}\end{array}$ & $\begin{array}{c}\text { B } \\
{[\mathrm{min}]}\end{array}$ & $\begin{array}{c}\mathrm{C} \\
{[\mathrm{L} / \mathrm{min}]}\end{array}$ & $\begin{array}{c}\text { Tensile strength } \\
{[\mathrm{MPa}]}\end{array}$ & $\begin{array}{c}\text { Tensile modulus } \\
{[\mathrm{MPa}]}\end{array}$ & $\begin{array}{c}\text { IFSS } \\
{[\mathrm{MPa}]}\end{array}$ \\
\hline 1 & -1 & -1 & -1 & 120 & 1.0 & 0.204 & 350.0 & 12.3 & 2.40 \\
\hline 2 & +1 & -1 & -1 & 170 & 1.0 & 0.204 & 340.0 & 12.0 & 3.00 \\
\hline 3 & -1 & +1 & -1 & 120 & 8.0 & 0.204 & 345.0 & 12.6 & 2.42 \\
\hline 4 & +1 & +1 & -1 & 170 & 8.0 & 0.204 & 335.0 & 12.4 & 2.30 \\
\hline 5 & -1 & -1 & +1 & 120 & 1.0 & 1,018 & 400.0 & 13.0 & 2.65 \\
\hline 6 & +1 & -1 & +1 & 170 & 1.0 & 1.018 & 380.0 & 12.7 & 2.35 \\
\hline 7 & -1 & +1 & +1 & 120 & 8.0 & 1.018 & 320.0 & 12.5 & 3.50 \\
\hline 8 & +1 & +1 & +1 & 170 & 8.0 & 1.018 & 310.0 & 12.7 & 2.60 \\
\hline 9 & 0 & 0 & 0 & 145 & 4.5 & 0.611 & 365.0 & 12.8 & 2.64 \\
\hline 10 & 0 & 0 & 0 & 145 & 4.5 & 0.611 & 367.0 & 12.7 & 2.63 \\
\hline 11 & 0 & 0 & 0 & 145 & 4.5 & 0.611 & 362.0 & 12.7 & 2.67 \\
\hline 12 & 0 & 0 & 0 & 145 & 4.5 & 0.611 & 364.0 & 12.1 & 2.62 \\
\hline 13 & 0 & 0 & 0 & 145 & 4.5 & 0.611 & 363.0 & 12.7 & 2.60 \\
\hline
\end{tabular}

coded in the dimensionless coordinate while as columns 5 to 7 give the natural variable levels.

A statistical analysis of the data was performed using the commercial software Design Expert 7, (Stat-Ease, Inc., Minneapolis, MN, USA). The analysis of variance (ANOVA) provided a study of the variation present in the results of the experiments carried out and the test of statistical significance, $p$ value, was determined according to the total error criteria considering a confidence level of $95 \%$. The influence of a factor is considered significant if the value of the critical level $(p)$ is lower than 0.05 ; discarding the meaningless parameters for $p$-values over 0.05 [30]. An empirical regression model encompassing all the operating variables and their binary interactions was calculated for the dependent variables, tensile strength, tensile modulus and IFSS between henequen fiber and HDPE.

\subsection{Mechanical properties}

\subsubsection{Tensile srength test}

Single-fiber tensile tests were conducted according to ASTM D3822-01 to determine the tensile strength of treated and untreated henequen fibers using a Shimadzu universal testing machine, Model AGS-X. A single fiber was selected and cut to a length of $30 \mathrm{~mm}$. The diameter of each henequen fiber tested was measured at several points along its length using an optical microscope Motic Digital Microscope DMI 43 before the test. The henequen fibers were conditioned at $60 \% \mathrm{RH}$ and a temperature of $25^{\circ} \mathrm{C}$ before they were tested. The gauge length was $12.5 \mathrm{~mm}$ and the cross-head speed was set to $1 \mathrm{~mm} / \mathrm{min}$. The results of 15 single fiber tests were evaluated in terms of tensile strength, tensile modulus and elongation at break.

\subsubsection{Interfacial shear strength test (pull-out test)}

To measure the IFSS the pull-out test was used. In this test, one end of the fiber is embedded in a block of the polymer matrix and a force is applied to the free end to pull it out of the matrix while the force is continuously monitored and recorded. The average IFSS can be calculated from the force at which the debonding occurs using Equation (3):

$\tau=\frac{F}{\pi d l}$

where $F$ is the maximum load measured prior to debonding of the fiber, $d$ is the fiber diameter and $l$ is the fiber embedded length [11, 14, 31, 32].

\subsubsection{Preparation of the pull-out test sample}

The pull-out specimens were made using the following procedure: the henequen fibers were attached to a frame using high temperature adhesive tape. Then, they were placed between two sheets of HDPE and the mold was subjected to a 1 ton constant pressure at $180^{\circ} \mathrm{C}$, in a Carver laboratory press for $10 \mathrm{~min}$ utes and then cooled to room temperature under constant pressure. The specimens were cut in rectangles of $3 \mathrm{~cm} \times 1 \mathrm{~cm}$ in such a way that one end of the fiber was embedded along the main axis of the rectangle. The nominal fiber embedded length was produced by perforating the sample at a specified position. The actual embedded length and the apparent diameter of the fiber of each probe were recorded with a Motic Digital Microscope DMI 43 (Cole 
Parmer Int., Vernon Hills, IL, USA) optical microscope. The specimens were subjected to a tensile force using a MINIMAT (Rheometric Scientific Inc., Piscataway, NJ., USA) miniature testing machine equipped with a $500 \mathrm{~N}$ load cell and the load-displacement curve was recorded using a cross-head speed of $1.2 \mathrm{~mm} / \mathrm{min}$. in all the experiments.

\subsection{Surface characterization}

\subsubsection{Infrared spectroscopy (FTIR)}

The henequen fibers were cut to an average length of $1.5 \mathrm{~mm}$ and then a FTIR analysis was performed on a Nicolet model Protege 460 Magna IR (Nicolet Inst. Corp., Madison, WI, USA) spectrometer using a Photoacoustic attachment (MTEC Photoacoustics, Inc., Ames, IA, USA). The spectra were recorded with $60 \mathrm{scans}, 4 \mathrm{~cm}^{-1}$ resolution a speed of $0.15 \mathrm{~cm} / \mathrm{s}$.

\subsubsection{Scanning electron microscopy (SEM)}

The henequen fibers were coated with gold and then analyzed using a JEOL JSM-6360LV (JEOL de Mex-

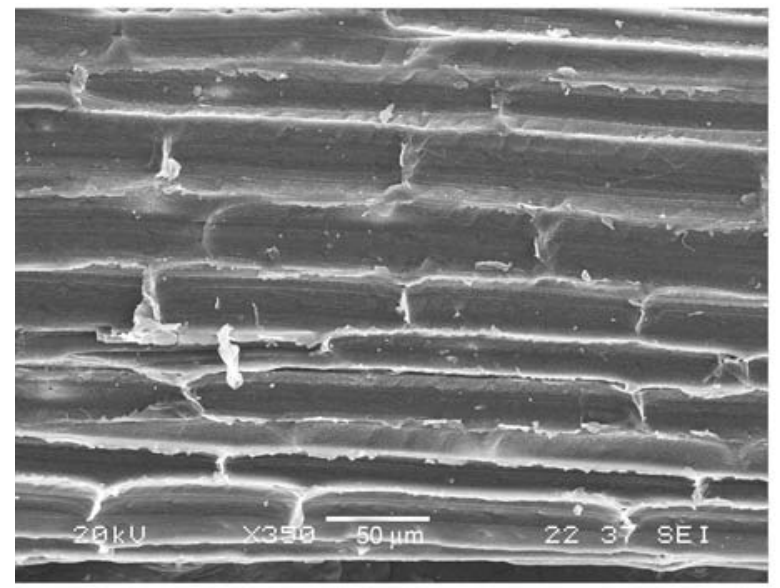

a)

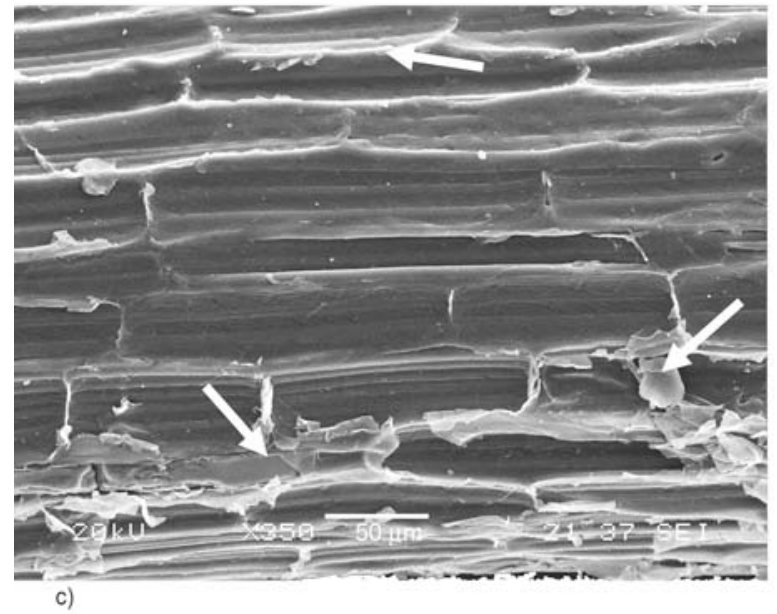

ico, D.F, MX) scanning electron microscope operated at $20 \mathrm{keV}$.

\section{Results and discussion 3.1. Surface characterization \\ 3.1.1. SEM analyses}

The surface morphology of the ethylene-plasma treated henequen fibers at different conditions of external operational parameters (frequency, exposure time, flow rate) of atmospheric pressure DBD ethylene-plasma are shown in Figure 1a-1d.

As it can be seen, the untreated fiber surface is relatively more homogeneous than the ethylene-plasma treated fibers. It can also be seen that there are some changes in the fiber topography that suggest an increment in fiber roughness and the formation of tiny cracks or cavities for the plasma treated fibers at conditions $(120,1.0,1.018)$, see Figure 1b, compared with the untreated ones displayed in Figure 1a. A rougher surface morphology and several defects in the form of cracks, pits and corrugations are pro-

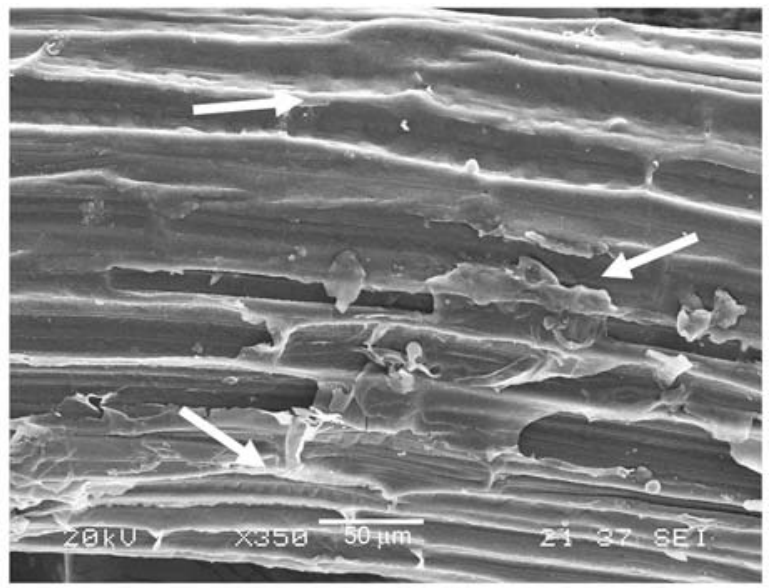

b)

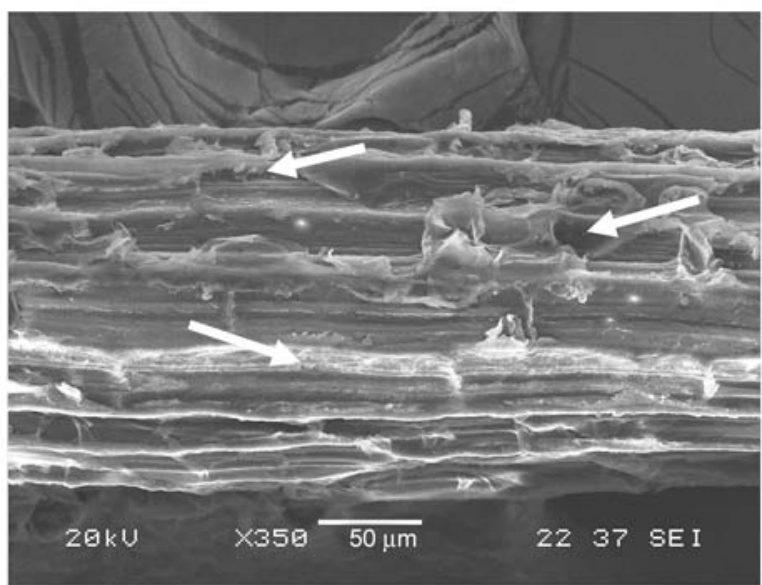

d)

Figure 1. SEM micrograph $(\times 350)$ showing the longitudinal section of henequen fibers (a) untreated; ethylene-plasma treated: (b) $(120,1.0,1.018)$; (c) $(170,1.0,1.018)$ and (d) $(170,8.0,1.018)$ 
duced in the fibers treated at $(170,1.0,1.018) \mathrm{can}$ be seen in Figure 1c. It is notorious that the increment in the frequency of discharges, results in an increase of the deterioration of the fiber surface because they are exposed to a greater amount of energy during its residence time on the DBD reactor. Also, the effect of exposure time on the fiber surface topography is evident in Figure 1d where it can be seen that the deterioration of the fiber surface is more severe for the fibers exposed during $8 \mathrm{~min}$ to the plasma discharges $(170,8,1.018)$. A large amount of crevices and torn microfibrils are evident because the longer the time of treatment, the more severe is the etching of the fiber surface than that resulting from the increase in the frequency of the discharge. These surface modifications are evident if Figures $1 \mathrm{c}$ and $1 \mathrm{~d}$ are compared. Furthermore, Figures $1 \mathrm{~b}-1 \mathrm{~d}$ also depict the presence of a thin layer of material (shown with arrows) indicating that exposure of the fibers to the ethylene plasma, induced the formation of a polymeric film. The amount of polymer deposited seems to be larger with the time of exposure (compare Figure $1 b$ to Figure 1d) than with an increment in the frequency of discharge (compare Figure $1 b$ to Figure 1c).

\subsection{FTIR analyses}

Figure 2 shows the infrared spectra of the ethyleneplasma treated curve (a); the untreated henequen fiber curve (b) and the difference between them curve (c). In Figures 2 curve $(a, b)$ it can be seen that both spectra, the untreated and the ethylene-plasma

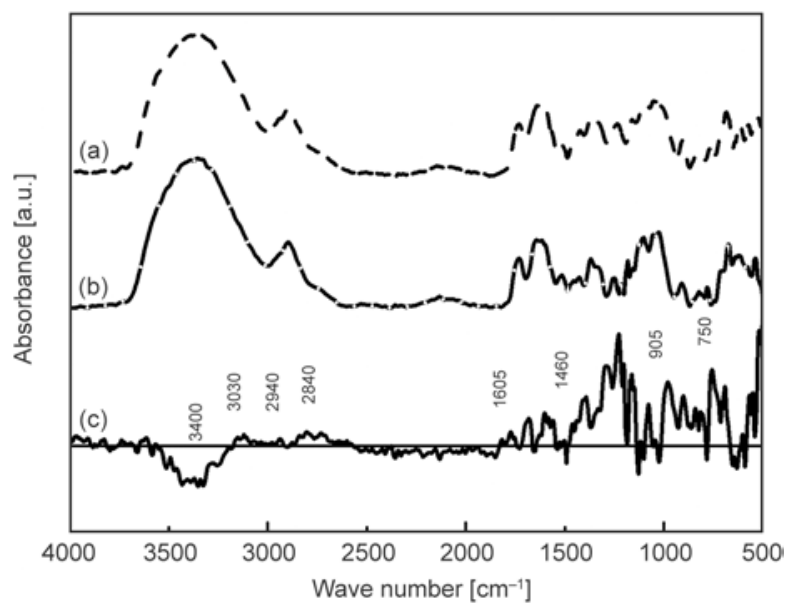

Figure 2. PAS-FTIR spectra of untreated and plasma treated henequen fibers. (a) Plasma treated (120, 1.0, 1.018); (b) untreated (pristine) fiber and (c) difference (a)-(b) spectrum. treated henequen fibers, are very similar and shows the absorbance peaks related to the characteristic functional groups of a lignocellulosic fiber. The broad and intense peak at $3400 \mathrm{~cm}^{-1}$ suggests hydrogenbonded $\mathrm{O}-\mathrm{H}$ stretching vibration from the cellulose and the lignin and to the water present on the fiber. The bands in the range $2800-3000 \mathrm{~cm}^{-1}$ are related to $\mathrm{C}-\mathrm{H}$ saturated hydrocarbon stretching. The shoulder at about 1730 is due to the carbonyl $(\mathrm{C}=\mathrm{O})$ stretching of acetyl groups of hemicellulose. The broad band around $1000-1300 \mathrm{~cm}^{-1}$ has been attributed to the $\mathrm{C}-\mathrm{O}-\mathrm{C}$ stretching vibration of cellulose and hemicellulose. [33, 34]. A more detailed analysis shows that definitely there are some differences between the spectra of the fibers processed in the plasma reactor and the untreated ones. In order to highlight these differences the subtraction of both spectra is plotted in Figure 2 curve (c).

It can be observed that there are changes in the $3000-3500,2800-3000 \mathrm{~cm}^{-1}$, and around 1600 , 1460, 900 and $750 \mathrm{~cm}^{-1}$. The decrease in the 3400 peak could be attributed to the reduction of the $\mathrm{O}-\mathrm{H}$ hydrogen bonds in the surface of the fiber due to an increment in its hydrophobicity, attributed to the deposition of a hydrocarbon polymeric film, formed during the exposure to the ethylene-plasma. The appearance of the peaks at $2940 \mathrm{~cm}^{-1}$ (asymmetric stretching) and $2840 \mathrm{~cm}^{-1}$ (symmetric stretching), the peak at $1460 \mathrm{~cm}^{-1}$ (bending) and the peak at $750 \mathrm{~cm}^{-1}$ (rocking deformation) of methylene group $\left(-\mathrm{CH}_{2}-\right)$ suggest the presence of a hydrocarbon film on the henequen fiber surface. Moreover, the peaks at 3030,1605 and at $905 \mathrm{~cm}^{-1}$ could be attributed to the existence of vinyl groups in the deposited film [35, 36]. Tibbit et al. [37], Donohoe and Wydeven [38], Oran et al. [39] and Swaraj et al. [40] have pointed out that the plasma polymerization of ethylene yields a plasma-polyethylene polymer with different structural characteristics with respect to that obtained with conventional methods. The plasmapolyethylene polymer possesses chemical crosslinks, ramifications and unsaturated vinyl groups.

\subsection{Fiber tensile test results}

The determination of tensile properties of henequen fibers is crucial because it gives a measure of how much improvement in mechanical properties can be expected when the fibers are incorporated in a polymer matrix. The sensitivity of henequen fibers to moisture content has been reported in the technical 


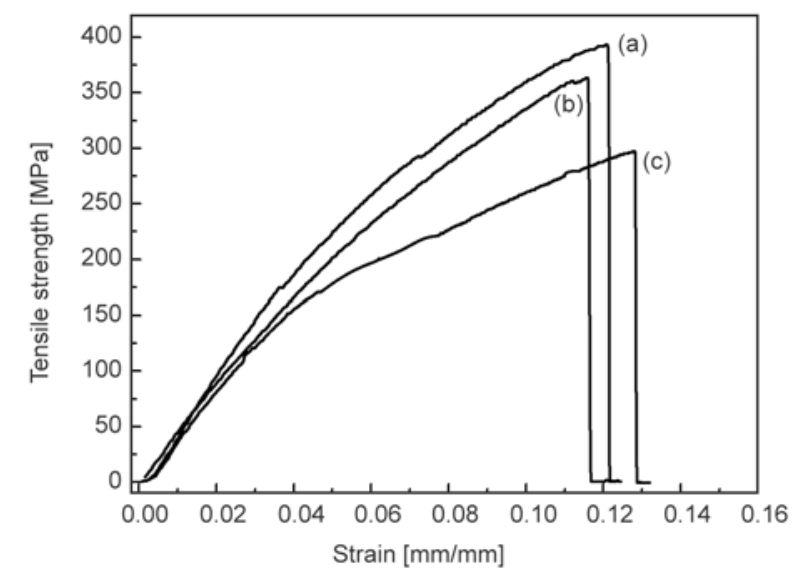

Figure 3. Typical stress-strain behavior of henequen fibers: (a) untreated; ethylene-plasma treated: (b) (120, $1.0,1.018)$ and (c) $(170,8,1.018)$

literature and it is known that the variation in moisture content can affect the tensile properties of fibers. Therefore, the fibers tested for tensile properties were equilibrated at $25^{\circ} \mathrm{C}$ and $60 \%$ relative humidity $(\mathrm{RH})$ before the testing. The typical stressstrain curve of henequen fiber in tensile testing is shown in Figure 3. The curves presented a non-linear region starting at stress levels of $50 \mathrm{MPa}$ or below. This non-linear region, following the initial portion of the stress-strain curve has been hypothesized to be due to a collapse of the weak primary cell walls and delamination between fiber-cells [10].

The knowledge of the internal structure of a henequen fiber [10] allows for the elaboration of an interpretation of its deformation mechanisms. The first linear zone of the stress-strain curve corresponds to a global loading of the cell walls. The curved zone can be associated to a visco-elasto-plastic deformation of the amorphous parts of the fiber together with an alignment of the cellulose microfibrils with the fiber axis. Finally, after this rearrangement, the third linear zone could be characteristic of the elastic deformation of the microfibrils. Ethyleneplasma treated fibers show a drop in the tensile strength and elongation at break that can be partially linked to the introduction of defects (e.g., cracks and pits) onto the surface of the fibers after plasma treatment, the longer the exposure to the plasma treatment the higher the flaw population.

\subsection{Interfacial shear strength test (pull out test) results}

The typical load-displacement curves for the pristine henequen fiber and subjected to two different

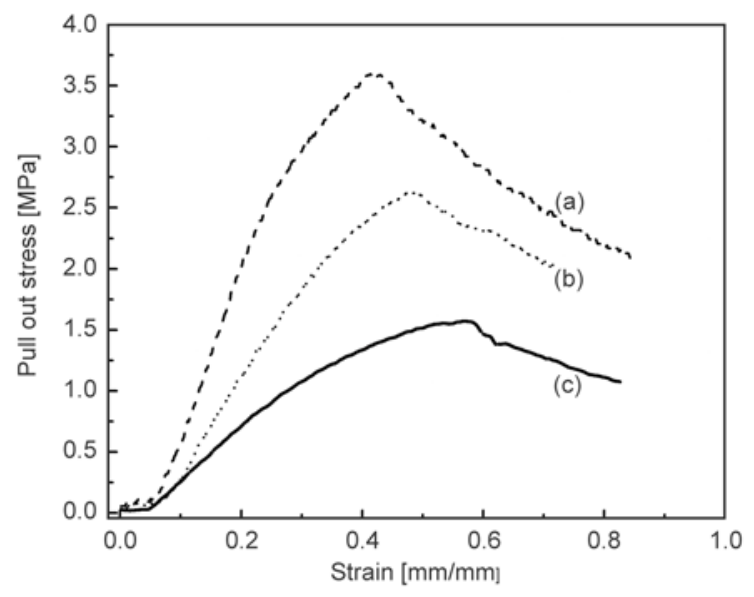

Figure 4. Typical average interfacial shear stress-strain behavior of henequen fibers subjected to different ethylene-plasma treatments: (a) $(120,1.0,1.018)$; (b) $(170,1.0,0.204)$ and (c) untreated

conditions on the ethylene-plasma reactor in the pull-out test are shown in Figure 4. It can be noted that all the curves exhibit the non-linear behavior characteristic of a ductile matrix [41].

However, once the load reaches its maximum value there are clearly significant differences in the way these curves drop. For the pristine henequen it can be seen that the load increases gradually and when it reaches a maximum value there is a smooth transition and it begins to decrease in a linear fashion until the total embedded length of the fiber is pulledout. This behavior agrees well with the behavior of a poor interphase that results because of the incompatibility between the hydrophilic fiber and the hydrophobic matrix. This behavior shows a slight change in the case of the henequen fibers treated at $(170,1.0,0.204)$ because the higher the roughness of the plasma treated fiber the better the fiber-matrix mechanical interlocking, i.e., the fiber-matrix interaction is improved. For the $(120,1.0,1.018)$ treated fiber, the load-displacement curve depicts better bonded interphase; after the interphase has failed, the fiber can still be extracted in a controlled way and friction was measured until the fiber was completely pulled-out. This behavior suggests a better fiber-matrix interlocking and to the possible interaction between the hydrocarbon film deposited onto the surface with the HDPE matrix [11, 14-16, 18-20]. Henequen fibers are polar hydrophilic lignocellulosic fibers because they have a chemical composition consisting of cellulose $(70 \% \mathrm{w} / \mathrm{w})$, hemicellulose $(20 \% \mathrm{w} / \mathrm{w})$, lignin $(8 \%)$ and extractives $(2 \%)$. Cellulose consists of long chains of anhydro-D-glu- 
copyranose units each bearing three hydroxyl groups (one primary and two secondary moieties), with the exception of the terminal ones. Valadez-Gonzalez et al. [9] have pointed out that pristine surface henequen fibers possess both acidic and basic sites since the surface acid-base characteristics of cellulose and lignin are different. While cellulose is strongly acidic, lignin is more evenly bipolar, with a much weaker acidity and a similar basicity than cellulose. The acetyl groups in the hemicelluloses also contribute to the basic character of the henequen fibers. On the other hand, High density Polyethylene is a nonpolar hydrophobic thermoplastic matrix due to the lack of reactive groups on its backbone chains and therefore only can interact by non-dispersive Van der Waals forces. Therefore, the adhesion between henequen fibers and HDPE is expected to be poor at the interface because of the different polarity. It is known that the surface treatments modify the fiber surface energy and so the nature of the fiber-matrix interphase. Several reports in the literature pointed out that the chemical surface treatment modifies the fiber surface free energy, i.e., it changes the surface dispersive and non-dispersive energies. Wettability, by a HDPE matrix, of henequen fibers can be improved by the action of ethylene plasma treatments, due to the reduction of the polar components of surface energy. The plasma-polymerized structure is usually complex but it is known that ethyl-

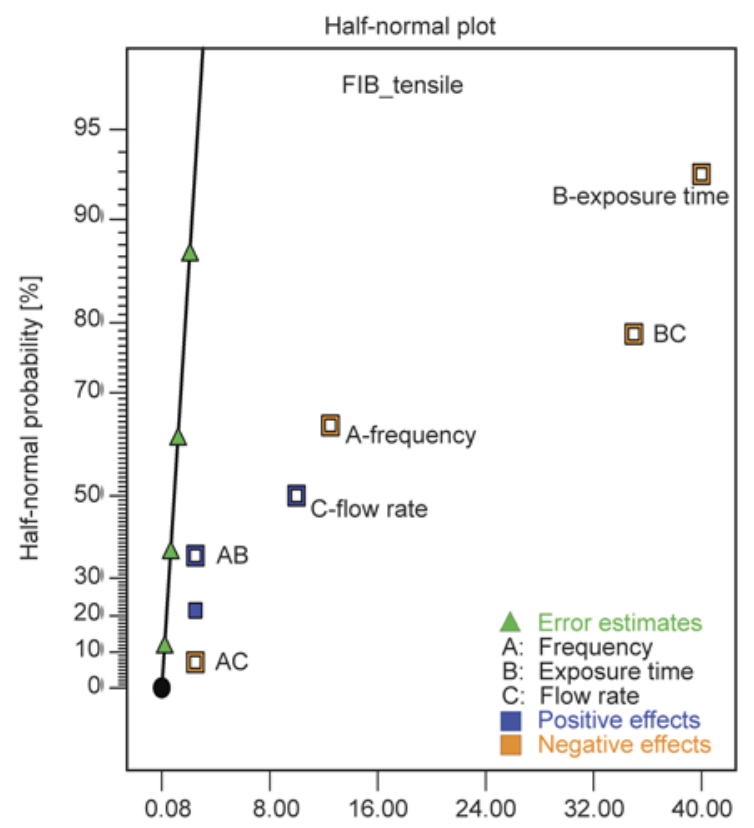

a)

[Standardized effect] ene-based plasma-polymerized structures are highly branched crosslinked and that they contain some degree of unsaturation [37].

\subsection{Factorial design analysis}

The experimental values obtained for the selected responses tensile strength, tensile modulus and interfacial shear strength (IFSS) are presented in Table 2.

\subsubsection{Model fitting and statistical analysis}

The half-normal probability plot for tensile strength and tensile modulus of henequen fibers and the related to the henequen-HDPE IFSS are shown in Figures $5 \mathrm{a}, 5 \mathrm{~b}$ and 6 respectively.

The half-normal probability plot is a graphical tool that uses the ordered estimated effects to help assess which factors are important and which are unimportant. From the half-normal probability plot of |effects| we should be able to identify the most important factors since the estimated |effect| of an unimportant factor will typically be on or close to a nearzero line, while the estimated |effect| of an important factor will typically be displaced well off the line. As can be seen in Figures 5a and 5b the exposure time is the most important plasma operational parameter for both tensile strength and modulus. Followed by the interaction time $\times$ flow rate; the frequency of discharge and last, the ethylene flow rate.

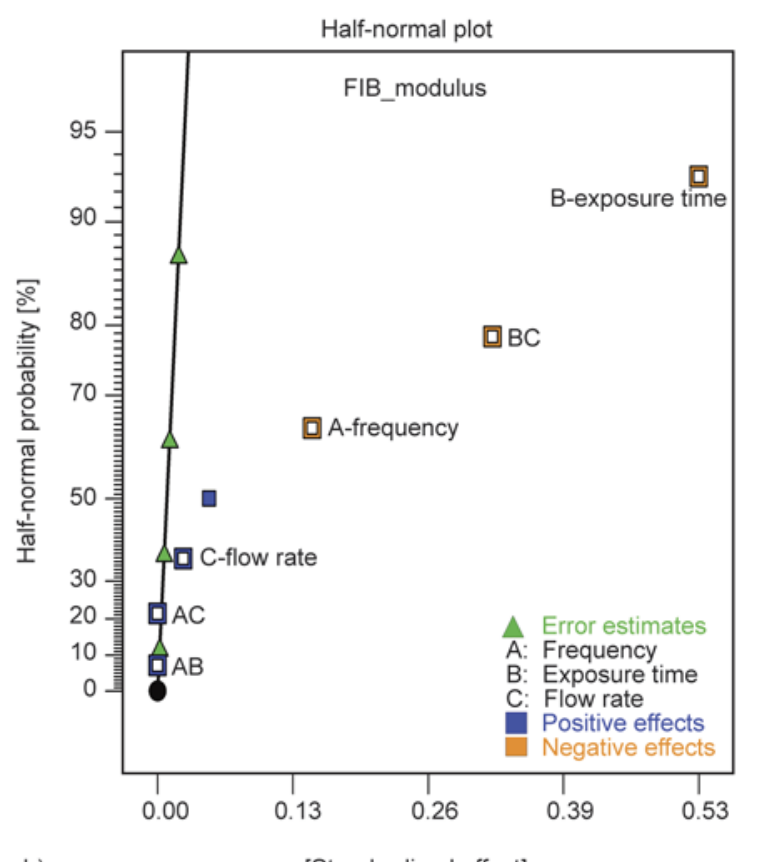

b)

[Standardized effect]

Figure 5. Half-normal probability plot showing the effects of plasma operational parameters on tensile properties of henequen fibers: (a) tensile strength and (b) tensile modulus 


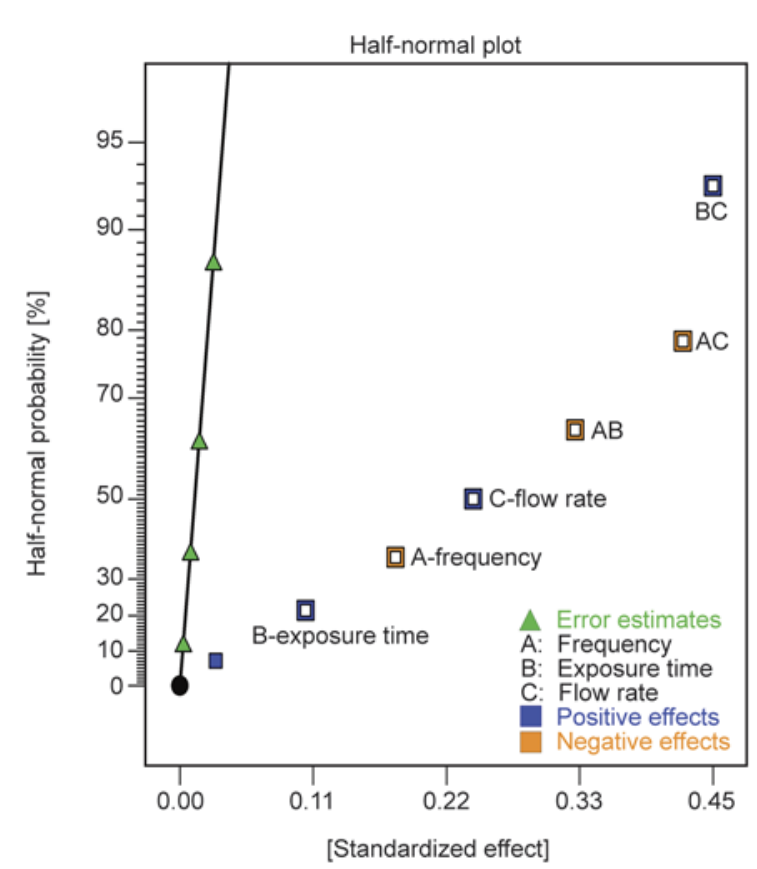

Figure 6. Half-normal probability plot showing the effects of plasma operational parameters on HenequenHDPE Interfacial Shear Strength (IFSS)

In the case of the IFSS, Figure 6, the three plasma operational parameters studied are significant. However it can be seen that the interaction time $\times$ flow rate is the most important whereas the frequency of discharges is the most important among the main effects.

The empirical relationships for tensile strength and tensile modulus as determined by Design-Expert software are shown in Equations (4), (5) and (6) below after eliminating the non-significant main effects and interaction terms:

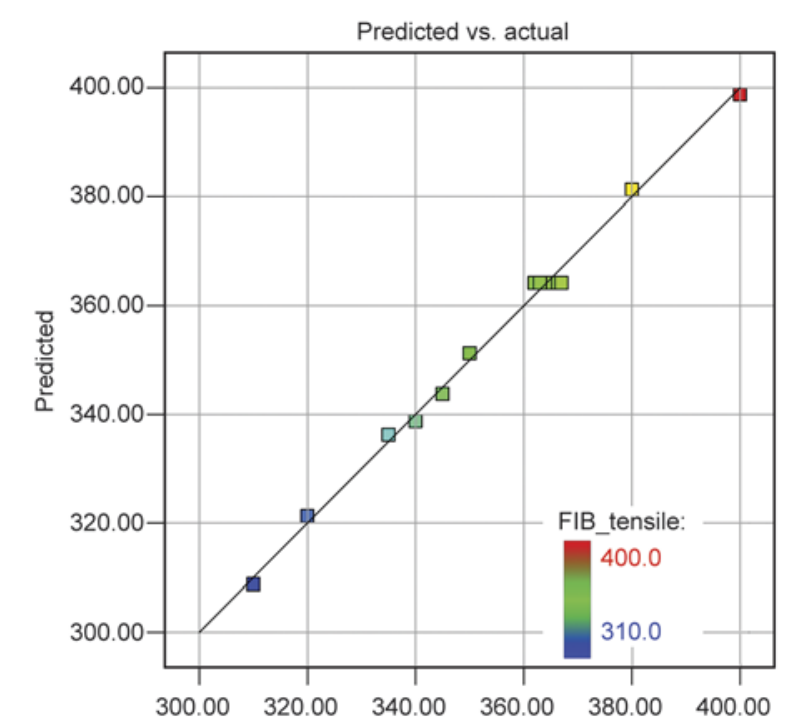

a)

Actual
FIB TENSILE $=$

$$
347.5-6.25 A-20.0 B+5.0 \mathrm{C}-17.5 B C
$$

FIB_MODULUS $=$

$$
12.46-0.075 A-0.26 B-0.16 B C
$$

IFSS_FIBPLASMA $=$

$$
\begin{aligned}
& 2.63-0.071 A+0.07 B+0.10 C-0.16 A B- \\
& 0.19 A C+0.24 B C
\end{aligned}
$$

The goodness of the regression model can be assessed because the excellent agreement between the experimental values and the predicted by the model as can be observed in the Figures $7 \mathrm{a}, 7 \mathrm{~b}$ and

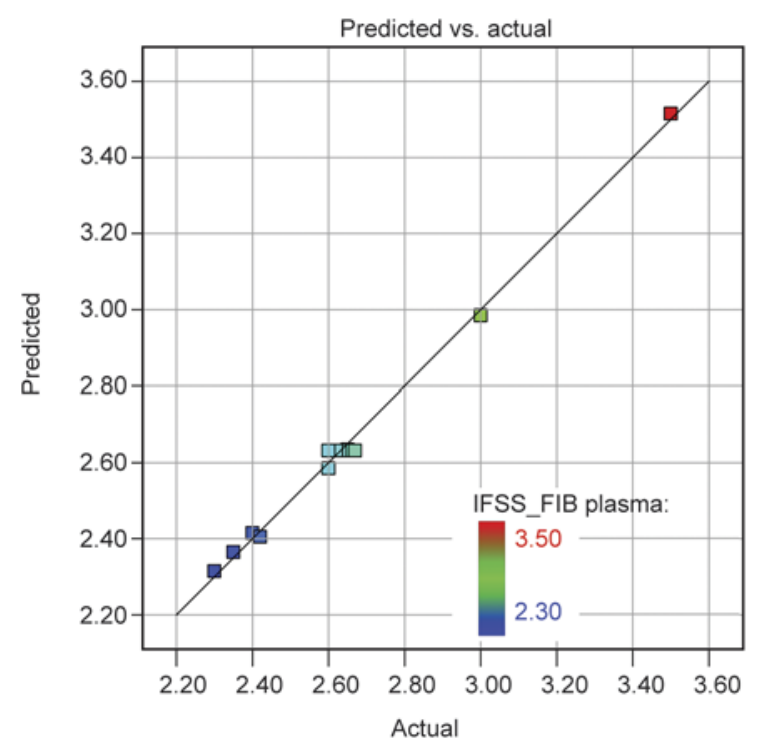

Figure 8. Scatter diagram of predicted response vs. actual response for interfacial shear strength of ethylene-plasma treated henequen fibers-HDPE

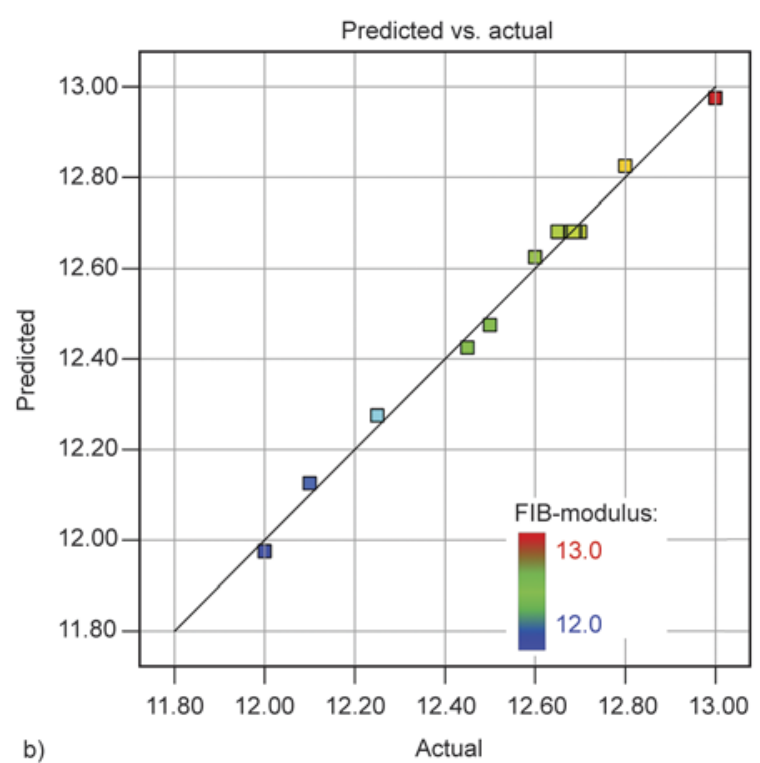

b)

Figure 7. Scatter diagram of predicted response vs. actual response for (a) tensile strength and (b) tensile modulus of ethylene-plasma treated henequen fibers 
for henequen fibers tensile strength and modulus respectively, and in Figure 8, for henequen-HDPE IFSS

\subsubsection{Response surface plot and contour plot analyses of tensile strength and modulus}

The response surfaces and contour plots are the graphical representations of regression equation. They provide a method to visualize the relationship between the response and each variable, and the interactions between any two tested variables. The fitted response surface plot was generated by statistically significant above model by Design-Expert program to understand the interaction of the operational plasma parameters selected (independent variables) on the tensile mechanical properties of henequen fibers and their interfacial shear strength with HDPE. The plots are shown in Figures 9-11 and were obtained from Equations (4), (5) and (6) respectively. Two parameters of each model were plotted at any one time on the $X$ and $Y$ axes with the response variable (tensile strength, modulus or IFSS) in $Z$ axis. The other remaining parameter was set constant. The shape of the contour plots (straight or curved) indicates whether the mutual interactions between variables are significant or not. A straight contour plot indicates that the interactions between related variables are negligible. A curved contour plot indicates that the interactions between related variables are significant. Analyses of the response surfaces and their respective contour plots allowed us to conveniently investigate the interactions between any two variables, and locate the optimum ranges of the variables efficiently such that the response was maximized. The contour plot and the

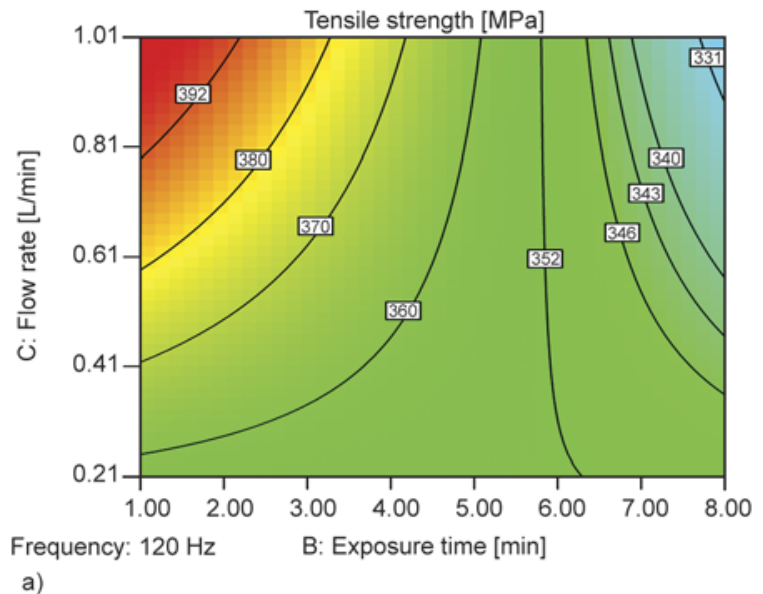

corresponding surface plot for tensile strength $[\mathrm{MPa}]$ of ethylene-plasma treated henequen fibers, as a function of the exposure time [min] and the ethylene-flow rate $[\mathrm{L} / \mathrm{min}]$ are shown in Figures 9a and $9 \mathrm{~b}$.

In Figure 9a it is observed that the highest fiber tensile strength was obtained at high flow rates and short exposure times. On another hand, the lowest fiber tensile strength value is found at high exposure times and high flow rates. This behavior highlights the importance of interaction between the operational parameters since the effect of flow rate depends on exposure time. At short times, $(1 \mathrm{~min})$, it increases the fiber strength whereas at longer times, $(8 \mathrm{~min})$, it decreases the fiber strength. We can observe how this strong interaction results in a 'twisting' of the surface response. Another fact that can be observed in Figure 9 is that the rate of change of the tensile strength is higher at short times compared with larger times, e.g. the sensibility of the process is greater at short times and more robust at longer ones.

The contour plot and the corresponding surface plot for tensile modulus [MPa] of ethylene-plasma treated henequen fibers, as function of exposure time [ $\mathrm{min}]$ and ethylene-flow rate $[\mathrm{L} / \mathrm{min}]$ are shown in Figures 10a and 10b. The general behavior of the tensile modulus is similar to that of tensile strength, i.e. the higher moduli were obtained at short times of exposure and high flow rates; the smaller moduli were found at longer times and high flow rates. However the interaction between both operational parameters, time of exposure and flow rate is weak as can be seen the more straight contour lines in Figure 10a. The corresponding surface plot is slightly

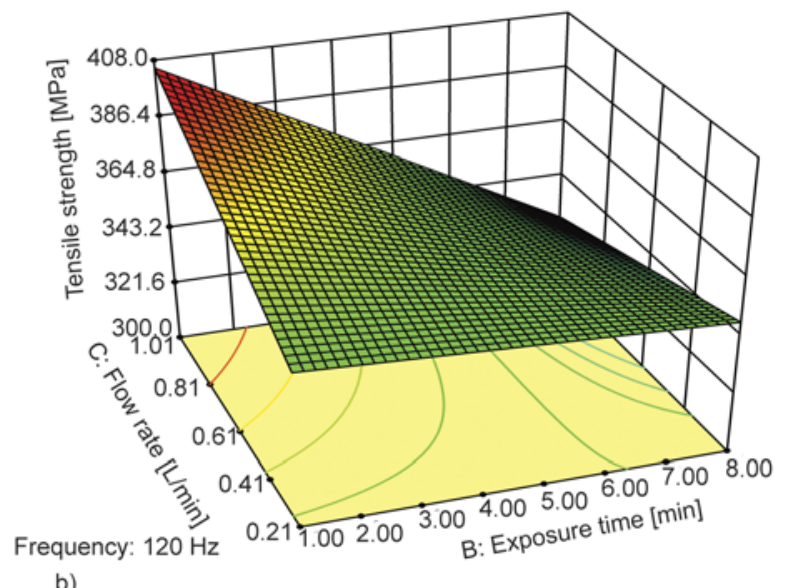

b)

Figure 9. Contour plot (a) and the corresponding surface plot (b) of tensile strength of ethylene-plasma treated henequen fibers 

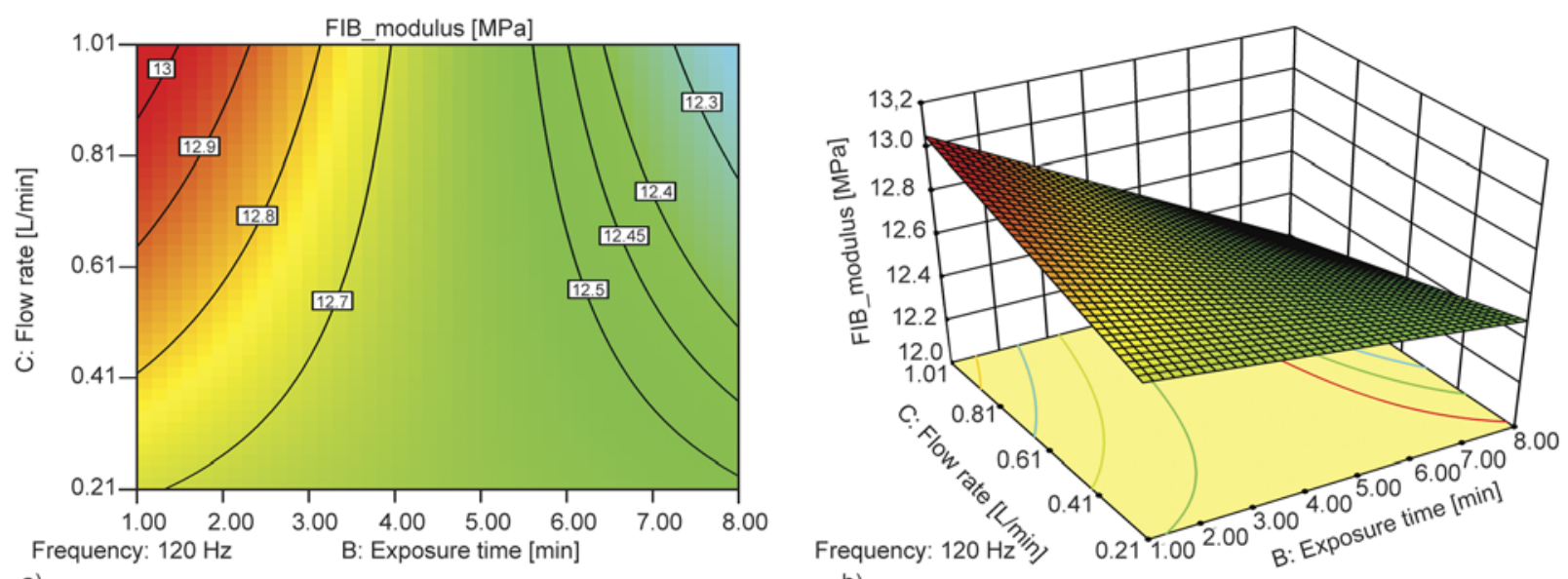

a)

b)

Figure 10. Contour plot (a) and the corresponding surface plot (b) of tensile modulus of ethylene-plasma treated henequen fibers

twisted and the rate of change of property is similar at short and high exposure times. For the tensile modulus concern, it seems that the process is robust. In other words the reactor condition for ethyleneplasma treatments slightly affects the henequen fiber modulus. The contour plot and the corresponding surface plot for interfacial shear strength [MPa] between henequen fiber and the HDPE tensile strength $[\mathrm{MPa}]$ of ethylene-plasma treated henequen fibers, as a function of exposure time [min] and ethylene-flow rate $[\mathrm{L} / \mathrm{min}]$ are shown in Figures 11a and 11b. In Figure 11a it is observed that the higher IFSS (3.5 MPa) between the ethylene-plasma henequen fibers and HDPE is accomplished at low frequency of discharges, high flow rate of ethylene and longer exposure times. On another hand, the smaller values of IFSS (2.3 MPa) were obtained at high frequency, longer exposure times and low flow rates. From these results it can be seen that we can improve the IFSS by approxi- mately $50 \%$ with a suitable choice of operational parameters of DBD plasma reactor. The contour lines shown in Figure 11a are curved, as can be expected, because the interaction flow rate-exposure time is statistically significant. Accordingly the surface response is twisted and shows a complex behavior at slow flow rates and short exposure times. Another fact that can be observed in Figure 11a is that the rate of change of IFSS is greater at longer exposure times than at short ones.

For example, increasing the ethylene flow rate from 0.21 to $1 \mathrm{~L} / \mathrm{min}$, it increases the IFSS from 2.4 to $2.46 \mathrm{MPa}(2.5 \%)$ at exposure times of $1 \mathrm{~min}$, whereas it increases from 2.43 to $3.4 \mathrm{MPa}(40 \%)$ at exposures time of $8 \mathrm{~min}$.

\section{Conclusions}

In order to improve the bonding between henequen fibers and High Density Polyethylene their surface modification was realized by exposing them to eth-
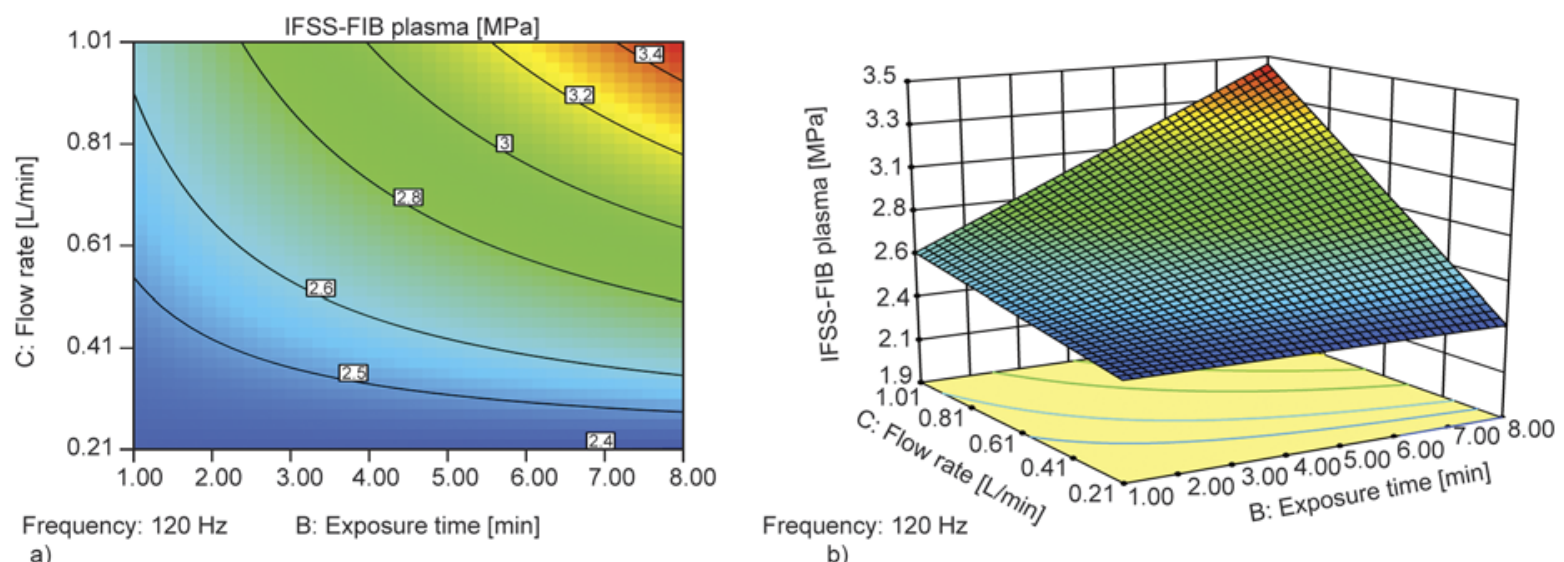

Figure 11. Contour plot (a) and the corresponding surface plot (b) for Interfacial shear strength of ethylene-plasma treated henequen fibers-HDPE 
ylene dielectric barrier discharge (DBD) plasma operating at atmospheric pressure. The present study indicates that individual operational parameters in DBD plasma treatment have different effects on the properties of henequen fibers and on its bonding with HDPE. The statistical analysis approach used here has determined that the chosen plasma operational parameters, frequency of discharges, exposure time and ethylene flow rate, have a selective effect on the nature and scale of the polymer modification that occurs in each case. The results shows that the conditions on the plasma reactor leads to a significant change in bonding between henequen fibers and HDPE as determined by the IFSS determined by means of the pull-out test. It was also found that the interactions between, exposure time-flow rate and frequency-flow rate, have more impact on the IFSS. The processing conditions that improve the IFSS to a great extent were frequency $120 \mathrm{~Hz}$, exposure time $8 \mathrm{~min}$ and ethylene flow rate $1.018 \mathrm{~L} / \mathrm{min}$. Also, if a frequency $170 \mathrm{~Hz}$, exposure time $8 \mathrm{~min}$ and flow rate $0.204 \mathrm{~L} / \mathrm{min}$ had been chosen, the IFSS would have dropped to its minimum value. The SEM results show that the exposure to plasma modifies the morphological properties of the fibers increasing their roughness. The FTIR results suggest the presence hydrocarbon-like polymer film, with some vinyl groups, that, it could react with the HDPE, deposited onto the fibers. These findings suggest that the improvement in the henequen-HDPE bonding could be the result of enhancing the mechanical interlocking, due the increment in roughness, and the possible reaction of the vinyl groups present in the hydrocarbon-like polymer film deposited onto the fiber.

\section{Acknowledgements}

The authors would like to thank Ms. I.Q. Silvia Beatriz Andrade Canto for the SEM micrographs and to M. en C. Javier Iván Cauich Cupul for assistance with the pull-out testing. The authors would also like to thank the support of the Bilateral Cooperation Mexico (CONACYT) Hungary (HAS) Program through grant No. 193207.

\section{References}

[1] Li X., Tabil L. G., Panigrahi S.: Chemical treatments of natural fiber for use in natural fiber-reinforced composites: A review. Journal of Polymers and the Environment, 15, 25-33 (2006). DOI: $\underline{10.1007 / \mathrm{s} 10924-006-0042-3}$
[2] Saheb D. N., Jog J. P.: Natural fiber polymer composites: A review. Advances in Polymer Technology, 18, 351-363 (1999).

DOI: 10.1002/(SICI)1098-2329(199924)18:4<351:: AID-ADV6>3.0.CO;2-X

[3] Biagiotti J., Puglia D., Torre L., Kenny J. M., Arbelaiz A., Cantero G., Marieta C., Llano-Ponte R., Mondragon I.: A systematic investigation on the influence of the chemical treatment of natural fibers on the properties of their polymer matrix composites. Polymer Composites, 25, 470-479 (2004).

DOI: $10.1002 /$ pc. 20040

[4] Kalia S., Thakur K., Celli A., Kiechel M. A., Schauer C. L.: Surface modification of plant fibers using environment friendly methods for their application in polymer composites, textile industry and antimicrobial activities: A review. Journal of Environmental Chemical Engineering, 1, 97-112 (2013).

DOI: $10.1016 /$ j.jece.2013.04.009

[5] Reddy M., Vivekanandhan S., Misra M., Bhatia S., Mohanty A. K.: Biobased plastics and bionanocomposites: Current status and future opportunities. Progress in Polymer Science, 38, 1653-1689 (2013).

DOI: $10.1016 / j$.progpolymsci.2013.05.006

[6] Neves Monteiro S., Duarte Lopes F., Paula Barbosa A., Barreto Bevitori A., Da Silva I. L. A., Lopes Da Costa L.: Natural lignocellulosic fibers as engineering materials - An overview. Metallurgical and Materials Transactions A, 42, 2011-2963 (2011).

DOI: $10.1007 / \mathrm{s} 11661-011-0789-6$

[7] Sobczak L., Brüggemann O., Putz R. F.: Polyolefin composites with natural fibers and wood-modification of the fiber/filler-matrix interaction. Journal of Applied Polymer Science, 127, 1-17 (2013).

DOI: 10.1002/app.36935

[8] Ho M-P., Wang H., Lee J-H., Ho C-K., Lau K-T., Leng J., Hui D.: Critical factors on manufacturing processes of natural fibre composites. Composites Part B: Engineering, 43, 3549-3562 (2012). DOI: $10.1016 /$ j.compositesb.2011.10.001

[9] Valadez-Gonzalez A., Moreno-Chulim M. V., HerreraFranco P. J.: Modification of the fibre surface for the optimisation of mechanical properties in natural-fibre reinforced polymers. International Journal of Materials and Product Technology, 36, 417-430 (2009). DOI: $10.1504 /$ IJMPT.2009.027846

[10] Cazaurang Martinez M. N., Herrera-Franco P. J., Gonzalez-Chi P. I., Aguilar-Vega M.: Physical and mechanical properties of henequen fibers. Journal of Applied Polymer Science, 43, 749-756 (1991). DOI: 10.1002/app.1991.070430412

[11] Valadez-González A., Cervantes-Uc J. M., Olayo R., Herrera-Franco P. J.: Effect of fiber surface treatment on the fiber-matrix bond strength of natural fiber reinforced composites. Composites Part B: Engineering, 30, 309-320 (1999). DOI: $10.1016 / \mathrm{S} 1359-8368(98) 00054-7$ 
[12] Valadez-González A., Cervantes-Uc J. M., Olayo R., Herrera-Franco P. J.: Chemical modification of henequen fibers with an organosilane coupling agent. Composites Part B: Engineering, 30, 321-331 (1999). DOI: 10.1016/S1359-8368(98)00055-9

[13] Khan M. A., Bhattacharia S. K., Kabir M. H., Chowdhury A. M. S. A., Rahman M. M.: Effect of mercerization on surface modification of henequen (Agave fourcroydes) fiber by photo-curing with 2-hydroxyethyl methacrylate (HEMA). Polymer Plastics Technology and Engineering, 44, 1079-1093 (2005).

DOI: $10.1081 /$ PPT-200065184

[14] Herrera-Franco P. J., Valadez-González A.: A study of the mechanical properties of short natural-fiber reinforced composites. Composites Part B: Engineering, 36, 597-608 (2005).

DOI: $10.1016 /$ j.compositesb.2005.04.001

[15] Colom X., Carrasco F., Pagès P., Cañavate J.: Effects of different treatments on the interface of HDPE/lignocellulosic fiber composites. Composites Science and Technology, 63, 161-169 (2003). DOI: $10.1016 / \mathrm{S} 0266-3538(02) 00248-8$

[16] George J., Sreekala M. S., Thomas S.: A review on interface modification and characterization of natural fiber reinforced plastic composites. Polymer Engineering and Science, 41, 1471-1485 (2001).

DOI: $10.1002 /$ pen.10846

[17] Corrales F., Vilaseca F., Llop M., Gironès J., Méndez J. A., Mutjè P.: Chemical modification of jute fibers for the production of green-composites. Journal of Hazardous Materials, 144, 730-735 (2007).

DOI: 10.1016/j.jhazmat.2007.01.103

[18] Pang Y., Cho D., Han S. O., Park W. H.: Interfacial shear strength and thermal properties of electron beamtreated henequen fibers reinforced unsaturated polyester composites. Macromolecular Research, 13, 453459 (2005).

DOI: $10.1007 / \mathrm{BF} 03218480$

[19] Lee H. S., Cho D., Han S. O.: Effect of natural fiber surface treatments on the interfacial and mechanical properties of henequen/polypropylene biocomposites. Macromolecular Research, 16, 411-417 (2008). DOI: $10.1007 / \mathrm{BF} 03218538$

[20] Choi H. Y., Han S. O., Lee J. S.: The effects of surface and pore characteristics of natural fiber on interfacial adhesion of henequen fiber/PP biocomposites. Composite Interfaces, 16, 359-376 (2009). DOI: $10.1163 / 156855409 X 450873$

[21] Denes F. S., Manolache S.: Macromolecular plasmachemistry: An emerging field of polymer science. Progress in Polymer Science, 29, 815-885 (2004). DOI: $10.1016 /$ j.progpolymsci.2004.05.001

[22] Goossens O., Dekempeneer E., Vangeneugden D., Van de Leest R., Leys C.: Application of atmospheric pressure dielectric barrier discharges in deposition, cleaning and activation. Surface and Coatings Technology, 142-144, 474-481 (2001). DOI: $\underline{10.1016 / \mathrm{S} 0257-8972(01) 01140-9}$
[23] Lee H. U., Jeong Y. S., Koh K. N., Jeong S. Y., Kim HG., Bae J. S., Cho C. R.: Contribution of power on cell adhesion using atmospheric dielectric barrier discharge (DBD) plasma system. Current Applied Physics, 9, 219-223 (2009).

DOI: $10.1016 /$ j.cap.2008.01.014

[24] Fanelli F., Fracassi F., d'Agostino R.: Deposition of hydrocarbon films by means of helium-ethylene fed glow dielectric barrier discharges. Plasma Processes and Polymers, 2, 688-694 (2005). DOI: $10.1002 /$ ppap. 200500057

[25] Heyse P., Dams R., Paulussen S., Houthoofd K., Janssen K., Jacobs P. A., Sels B. F.: Dielectric barrier discharge at atmospheric pressure as a tool to deposit versatile organic coatings at moderate power input. Plasma Processes and Polymers, 4, 145-157 (2007). DOI: $10.1002 /$ ppap.200600087

[26] de Valence S., Tille J-C., Chaabane C., Gurny R., Bochaton-Piallat M-L., Walpoth B. H., Möller M.: Plasma treatment for improving cell biocompatibility of a biodegradable polymer scaffold for vascular graft applications. European Journal of Pharmaceutics and Biopharmaceutics, 85, 78-86 (2013).

DOI: $10.1016 /$ j.ejpb.2013.06.012

[27] Kaklamani G., Bowen J., Mehrban N., Dong H., Grover L. M., Stamboulis A.: Active screen plasma nitriding enhances cell attachment to polymer surfaces. Applied Surface Science, 273, 787-798 (2013). DOI: $10.1016 /$ j.apsusc. 2013.03.001

[28] Parvinzadeh Gashti M., Hegemann D., Stir M., Hulliger J.: Thin film plasma functionalization of polyethylene terephthalate to induce bone-like hydroxyapatite nanocrystals. Plasma Processes and Polymers, 11, 3743 (2014).

DOI: $10.1002 /$ ppap. 201300100

[29] Toriz G., Gutiérrez M. G., González-Alvarez V., Wendel A., Gatenholm P., de J. Martínez-Gómez A.: Highly hydrophobic wood surfaces prepared by treatment with atmospheric pressure dielectric barrier discharges. Journal of Adhesion Science and Technology, 22, 2059-2078 (2008).

DOI: $10.1163 / 156856108 \times 332561$

[30] Montgomery D. C.: Design and analysis of experiments. Wiley, New Jersey (2005).

[31] Li J-X.: Analysis of the pullout of single fibers from low-density polyethylene. Journal of Applied Polymer Science, 53, 225-237 (1994).

DOI: 10.1002/app.1994.070530211

[32] Stamboulis A., Baillie C., Schulz E.: Interfacial characterisation of flax fibre-thermoplastic polymer composites by the pull-out test. Die Angewandte Makromolekulare Chemie, 272, 117-120 (1999).

DOI: 10.1002/(SICI)1522-9505(19991201)272:1<117 ::AID-APMC117>3.0.CO;2-9 
[33] Matuana L. M., Balatinecz J. J., Sodhi R. N. S., Park C. B.: Surface characterization of esterified cellulosic fibers by XPS and FTIR spectroscopy. Wood Science and Technology, 35, 191-201 (2001).

DOI: $10.1007 / \mathrm{s} 002260100097$

[34] Baltazar-y-Jimenez A., Bistritz M., Schulz E., Bismarck A.: Atmospheric air pressure plasma treatment of lignocellulosic fibres: Impact on mechanical properties and adhesion to cellulose acetate butyrate. Composites Science and Technology, 68, 215-227 (2008). DOI: $10.1016 /$ j.compscitech.2007.04.028

[35] Gulmine J. V, Janissek P. R., Heise H. M., Akcelrud L.: Polyethylene characterization by FTIR. Polymer Testing, 21, 557-563 (2002).

DOI: $10.1016 / \mathrm{S} 0142-9418(01) 00124-6$

[36] Morrison W. H., Himmelsbach D. S., Akin D. E., Evans J. D.: Chemical and spectroscopic analysis of lignin in isolated flax fibers. Journal of Agricultural and Food Chemistry, 51, 2565-2568 (2003). DOI: $10.1021 / \mathrm{jf0} 20885 \mathrm{t}$

[37] Tibbitt J. M., Shen M., Bell A. T.: Structural characterization of plasma-polymerized hydrocarbons. Journal of Macromolecular Science: Part A Chemistry, 10, 1623-1648 (1976).

DOI: $10.1080 / 00222337608060775$
[38] Donohoe K. G., Wydeven T.: Plasma polymerization of ethylene in an atmospheric pressure-pulsed discharge. Journal of Applied Polymer Science, 23, 2591-2601 (1979). DOI: 10.1002 app.1979.070230905

[39] Oran U., Swaraj S., Friedrich J. F., Wolfgang U. E. S.: Surface analysis of plasma-deposited polymer films, 3a, in situ characterization of plasma-deposited ethylene films by ToF-SSIMS. Plasma Processes and Polymers, 1, 141-152 (2004). DOI: $10.1002 /$ ppap. 200400025

[40] Swaraj S., Oran U., Lippitz A., Schulze R-D., Friedrich J. F., Unger W. E. S.: Surface analysis of plasmadeposited polymer films, 4a, In situ characterization of plasma-deposited ethylene films by XPS and NEXAFS. Plasma Processes and Polymers, 2, 310-318 (2005).

DOI: $10.1002 /$ ppap.200400070

[41] Désarmot G., Favre J-P.: Advances in pull-out testing and data analysis. Composites Science and Technology, 42, 151-187 (1991). DOI: 10.1016/0266-3538(91)90016-I 